\title{
Exercise training in childhood-onset systemic lupus erythematosus: a controlled randomized trial
}

\author{
Danilo ML Prado ${ }^{1}$, Fabiana B Benatti ${ }^{1,2}$, Ana L de Sá-Pinto ${ }^{1}$, Ana P Hayashi ${ }^{1}$ Bruno Gualano ${ }^{1,2}$, Rosa MR Pereira ${ }^{1}$,
} Adriana ME Sallum ${ }^{3}$, Eloisa Bonfá ${ }^{1}$, Clovis A Silva ${ }^{3}$ and Hamilton Roschel ${ }^{1,2^{*}}$

\begin{abstract}
Introduction: Exercise training has emerged as a promising therapeutic strategy to counteract physical dysfunction in adult systemic lupus erythematosus. However, no longitudinal studies have evaluated the effects of an exercise training program in childhood-onset systemic lupus erythematosus (C-SLE) patients. The objective was to evaluate the safety and the efficacy of a supervised aerobic training program in improving the cardiorespiratory capacity in C-SLE patients.
\end{abstract}

Methods: Nineteen physically inactive C-SLE patients were randomly assigned into two groups: trained (TR, $n=10$, supervised moderate-intensity aerobic exercise program) and non-trained (NT, $n=9)$. Gender-, body mass index (BMI)- and age-matched healthy children were recruited as controls $(C, n=10)$ for baseline (PRE) measurements only. C-SLE patients were assessed at PRE and after 12 weeks of training (POST). Main measurements included exercise tolerance and cardiorespiratory measurements in response to a maximal exercise (that is, peak $\mathrm{VO}_{2}$, chronotropic reserve $(C R)$, and the heart rate recovery $(\triangle H R R)$ (that is, the difference between HR at peak exercise and at both the first ( $\triangle \mathrm{HRR} 1)$ and second ( $\triangle \mathrm{HRR2}$ ) minutes of recovery after exercise).

Results: The C-SLE NT patients did not present changes in any of the cardiorespiratory parameters at POST $(P>$ 0.05). In contrast, the exercise training program was effective in promoting significant increases in time-toexhaustion $(P=0.01$; $E S=1.07)$, peak speed $(P=0.01$; $E S=1.08)$, peak $V_{2}(P=0.04 ; E S=0.86), C R(P=0.06 ; E S=$ 0.83), and in $\triangle H R R 1$ and $\triangle H R R 2(P=0.003 ; E S=1.29$ and $P=0.0008 ; E S=1.36$, respectively $)$ in the C-SLE TR when compared with the NT group. Moreover, cardiorespiratory parameters were comparable between C-SLE TR patients and $C$ subjects after the exercise training intervention, as evidenced by the ANOVA analysis ( $P>0.05, T R$ vs. $C$ ). SLEDAI-2K scores remained stable throughout the study.

Conclusion: A 3-month aerobic exercise training was safe and capable of ameliorating the cardiorespiratory capacity and the autonomic function in C-SLE patients.

Trial registration: NCT01515163.

\section{Introduction}

Systemic lupus erythematosus (SLE) is a life-long systemic autoimmune disease with a large variability in its clinical course. The onset of SLE during childhood and adolescence represents 10 to $20 \%$ of all SLE cases [1] and is associated with a more severe disease course compared

\footnotetext{
*Correspondence: hars@usp.br

'Division of Rheumatology, School of Medicine, University of Sao Paulo, Av. Dr. Eneas de Carvalho Aguiar, 255 - Sao Paulo, SP, CEP 05403-000, Brazil Full list of author information is available at the end of the article
}

to adult SLE. Due to earlier diagnosis as well as significant advances in the management of childhood-onset SLE (C-SLE), mortality rates have greatly decreased, with an estimated 5- to 10-year survival rate of over $85 \%$ [2]. As a consequence, there has been a great increase in long-term co-morbidities, particularly cardiovascular disease (CVD), which is currently considered a major cause of long-term mortality in C-SLE patients [3].

Both disease-related (namely, long-term corticosteroid use, systemic inflammation, and autonomic dysfunction)

\section{Biomed Central}


and traditional factors (namely, lipid abnormalities, diabetes mellitus, and hypertension) have been implicated in the increased CVD risk in SLE [4-7]. Additionally, SLE patients commonly present a reduced exercise capacity and physical function [8-12], which may further increase CVD and mortality risk [13].

In this context, exercise training has emerged as a potential non-pharmacological therapeutic strategy to counteract physical dysfunction in adult SLE [8,9,14-16], although no studies have been conducted with C-SLE patients. It is well-known that exercise-induced adaptations largely differ between adults and children. This holds true for a variety of training variables, including (but not limited to) maximal aerobic capacity, mechanical efficiency and economy of movement, anaerobic capacity, exercise recovery, cardiovascular response, strength, immune response, morphological adaptations, detraining, metabolic responses, thermal regulation, etcetera. Such discrepant responses rely on physiological, metabolic, maturational, social, affective, and perceptual characteristics that are unique to pediatric populations [17]. Additionally, it has been also recognized that C-SLE patients may show differential features compared with adult counterparts, especially in regard to clinical symptoms and treatment response [18-21]. In light of these factors, one may suggest that the exercise training-induced outcomes found in the adult SLE population cannot be promptly generalized to C-SLE, thus warranting studies in this specific population.

A few studies have demonstrated the beneficial role of exercise in other pediatric rheumatic diseases, including juvenile dermatomyositis (JDM) [22,23] and fibromyalgia [24]. Furthermore, we recently demonstrated that a threemonth supervised aerobic training program was effective in improving the aerobic capacity and the physical function of a 15-year-old boy with C-SLE associated with secondary antiphospholipid syndrome [25]. However, to the best of our knowledge, no longitudinal studies have evaluated the potential therapeutic effects of an exercise training program in the C-SLE population [26].

Thus, the aim of the present study was to evaluate the safety and the efficacy of a 12-week supervised aerobic training program in improving the cardiorespiratory capacity in C-SLE patients.

\section{Materials and methods Experimental design and patients}

A 12-week randomized trial was conducted between May 2010 and April 2011 at the Laboratory of Physical Conditioning in Rheumatology of the School of Medicine, University of Sao Paulo, Brazil. This trial was registered at clinicaltrials.gov as NCT01515163. The sample consisted of children and adolescents with C-SLE from the outpatient ambulatory of the Pediatric Rheumatology Division of the Children's Institute of the School of
Medicine, University of Sao Paulo, Brazil, who were randomly assigned to participate in a three-month supervised exercise training program (trained, TR) or to remain physically inactive (non-trained, NT). Randomization was accomplished through a block randomization procedure with block sizes of four individuals. Body mass index-, gender- and age-matched healthy children from the surrounding community were recruited as controls (C). The patients fulfilled the revised American College of Rheumatology criteria [27] for C-SLE. The inclusion criteria were: age between 7 and 15 years, and Systemic Lupus Erythematosus Disease Activity Index (SLEDAI)-2K score $\leq 16$. Exclusion criteria included neuropsychiatry involvement, hematologic abnormalities, cardiovascular rhythm and conduction disorders, musculoskeletal disturbances that precluded participation in physical exercise, pleuritis, pericarditis, endocarditis, acute kidney failure, use of tobacco, treatment with lipid-lowering drugs, secondary fibromyalgia. Healthy control subjects were not taking any medication. C-SLE patients had not engaged in regular physical activity programs at least 6 months prior to the study. Importantly, the healthy control subjects were engaged only in the physical education classes in school (a 45-minute session twice a week).

At baseline (PRE) and 12 weeks after the intervention (POST), clinical (that is SLEDAI-2K [28] and Systemic Lupus International Collaborating Clinics/ACR Damage Index (SLICC/ACR-DI) [29], and laboratory parameters (namely, erythrocyte sedimentation rate (ESR), C-reactive protein (CRP), complements 3 and 4 (C3 and C4) and anti-dsDNA antibodies), cardiorespiratory measurements in response to a maximal graded exercise, body composition, and bone mineral density (BMD) were assessed in the C-SLE patients. Healthy children and adolescents were assessed for the same aforementioned parameters only at baseline. The study was approved by the Committee of Ethics in Research of the General Hospital of the School of Medicine, University of Sao Paulo, Brazil (CAPPesq) and all of the subjects' parents signed the informed consent.

\section{Exercise training program}

The exercise program consisted of 12 weeks of twiceweekly supervised moderate-intensity aerobic exercise training. Training sessions comprised a 5-minute warmup followed by 20 to 50 minutes of treadmill aerobic training (a 10-minute increment in the aerobic training volume was applied every four weeks), and 5 minutes of cooldown on the treadmill at a low speed followed by stretching exercises. All of the training sessions were monitored by at least one fitness professional and a Rheumatologist monitored adverse events on a weekly basis. The exercise program was performed in an intra-hospital gymnasium. Aerobic training intensity was set at the corresponding 
heart rate between the ventilatory anaerobic threshold (VAT) and 10\% below the respiratory compensation point (RCP). All of the patients were able to achieve the set aerobic training intensity.

\section{Cardiorespiratory exercise test}

The cardiorespiratory exercise test was performed on a treadmill (Centurion, model 200, Micromed, Brazil), using a maximal graded exercise protocol [30]. The treadmill speed (2.0, 2.5, 3.0, 3.5, 4.0, 4.0, 4.0, 4.0, 5.0, 5.4, 5.9, 6.3, $6.3 \mathrm{mph}$ ), or grade $(0.0,0.0,0.0,0.0,0.0,2.5,5.0,7.5,4.0$, $4.0,4.0,4.0 .5 .8 \%)$ was increased every 1 minute. The recovery period was set at 2 minutes. Oxygen consumption $\left(\mathrm{VO}_{2}\right)$ and carbon dioxide output were obtained through breath-by-breath sampling and expressed as a 30 -second average using an indirect calorimetry system (Cortex, model Metalyzer III B, Leipzig, Germany). Heart Rate (HR) was continuously recorded at rest, during exercise, and at recovery, using a 12-lead electrocardiogram (Ergo PC Elite, InC. Micromed, Brasília, DF, Brazil). Peak oxygen consumption (peak $\mathrm{VO}_{2}$ ), VAT and RCP were determined according to previously described criteria [30]. The test was deemed complete when despite verbal encouragement, the child was unable to continue exercising. The following criteria were used to define maximal effort: 1) subjective evidence of exhaustion and either 2) peak HR > 190 beats/minute, or 3) maximal respiratory exchange ratio $($ RER) $>1.00$ [31].

\section{$H R$ response during exercise and recovery}

HR response during exercise was evaluated by the chronotropic reserve (CR) as follows [32]:

$$
((\mathrm{CR})=(\text { Peak HR }- \text { Resting HR/208 }-(0.7 * \text { Age })-\text { Resting HR }] \times 100) .
$$

HR recovery was defined as the difference between $H R$ at peak and at both the first $(\triangle H R R 1)$ and second $(\Delta$ HRR2) minutes after exercise. Absolute change $(\Delta)$ was used to calculate the difference between the HR at peak exercise and at the first and second minutes after the exercise test. The relative change in HR $(\Delta \%)$ was calculated for the intervals between rest to VAT, rest to $\mathrm{RCP}$, and rest to peak exercise.

\section{BMD and body composition}

$\operatorname{BMD}\left(\mathrm{g} / \mathrm{cm}^{2}\right)$ was determined by dual-energy $\mathrm{x}$-ray absorptiometry (DXA), using a Hologic QDR 4500 Discovery densitometer (Hologic Inc., Bedford, MA, USA). Bone area $(\mathrm{BA})\left(\mathrm{cm}^{2}\right)$ was calculated using the software provided with the densitometer. Bone mass was analyzed in the lumbar spine (lumbar vertebrae L1 to L4), total femur, and whole body. The whole-body analysis was conducted without including the head, as it has been described to increase variability in children [33]. To minimize the confounding effect of skeletal size on DXA measurements, a volumetric, three-dimensional approximation of bone density was calculated (that is, bone mineral apparent density (BMAD) in $\mathrm{g} / \mathrm{cm}^{3}$ ). BMAD was assessed by dividing the BMD in a given site (the lumbar spine, total femur, or whole body) by the square root of the corresponding bone area $(\mathrm{BA})(\mathrm{BMAD}=\mathrm{BMD} / \sqrt{\mathrm{BA}})$ [34]. All of the measurements were performed by the same trained technologist. Precision error for BMD measurements was determined according to the standards in the International Society for Clinical Densitometry protocols [35]. Least significant changes with $95 \%$ confidence were $0.033 \mathrm{~g} / \mathrm{cm}^{2}$ at the lumbar spine, $0.039 \mathrm{~g} / \mathrm{cm}^{2}$ at the total femur, and $0.020 \mathrm{~g} /$ $\mathrm{cm}^{2}$ at the whole body. Body composition (that is, lean mass and fat mass) was assessed through the same densitometer, using pediatric software.

\section{Statistical analysis}

The data are presented as means and SDs. Fisher's exact test was used to assess baseline differences between the $\mathrm{C}$-SLE groups in the drug regimen. The disease-related parameters (SLEDAI-2K, SLICC/ACR-DI, disease duration, and current and cumulative dose of drugs) at baseline were compared using the Student's $t$-test. After the normality and homogeneity of the variance were confirmed, the dependent variables were compared using a mixed model for repeated measures, assuming groups and time as fixed factors and subjects as random factors. Single degree of freedom contrasts were used to determine significant differences between groups. Finally, effect sizes (ES) were estimated for the POST assessments using the pooled SDs of the two independent samples at POST [36]. The significance level was set at $P<$ 0.05. All of the analyses were performed using SAS 9.2, SAS Institute Inc., Cary, NC, USA.

\section{Results}

\section{Patients}

Twenty C-SLE patients were randomly assigned to the experimental groups ( $\mathrm{TR}=10$ and $\mathrm{NT}=10)$. One patient from the NT group withdrew from the study due to personal reasons and was excluded from the analysis. Thus, 19 patients were included in the analysis $(\mathrm{TR}=10, \mathrm{NT}=9)$ (Figure 1). Ten healthy subjects were included in the healthy control group $(C=10)$. Table 1 shows the demographic data of the C-SLE patients and healthy control subjects at baseline. The groups were similar in age, weight, height, $\mathrm{BMI}$ values, and drug regime at baseline $(P>0.05)$. The exercise adherence rate was $94.0 \pm 7.03 \%$.

\section{Exercise tolerance and cardiorespiratory measurements at baseline}

The exercise and cardiorespiratory parameters at baseline are shown in Table 2. The C-SLE patients presented 


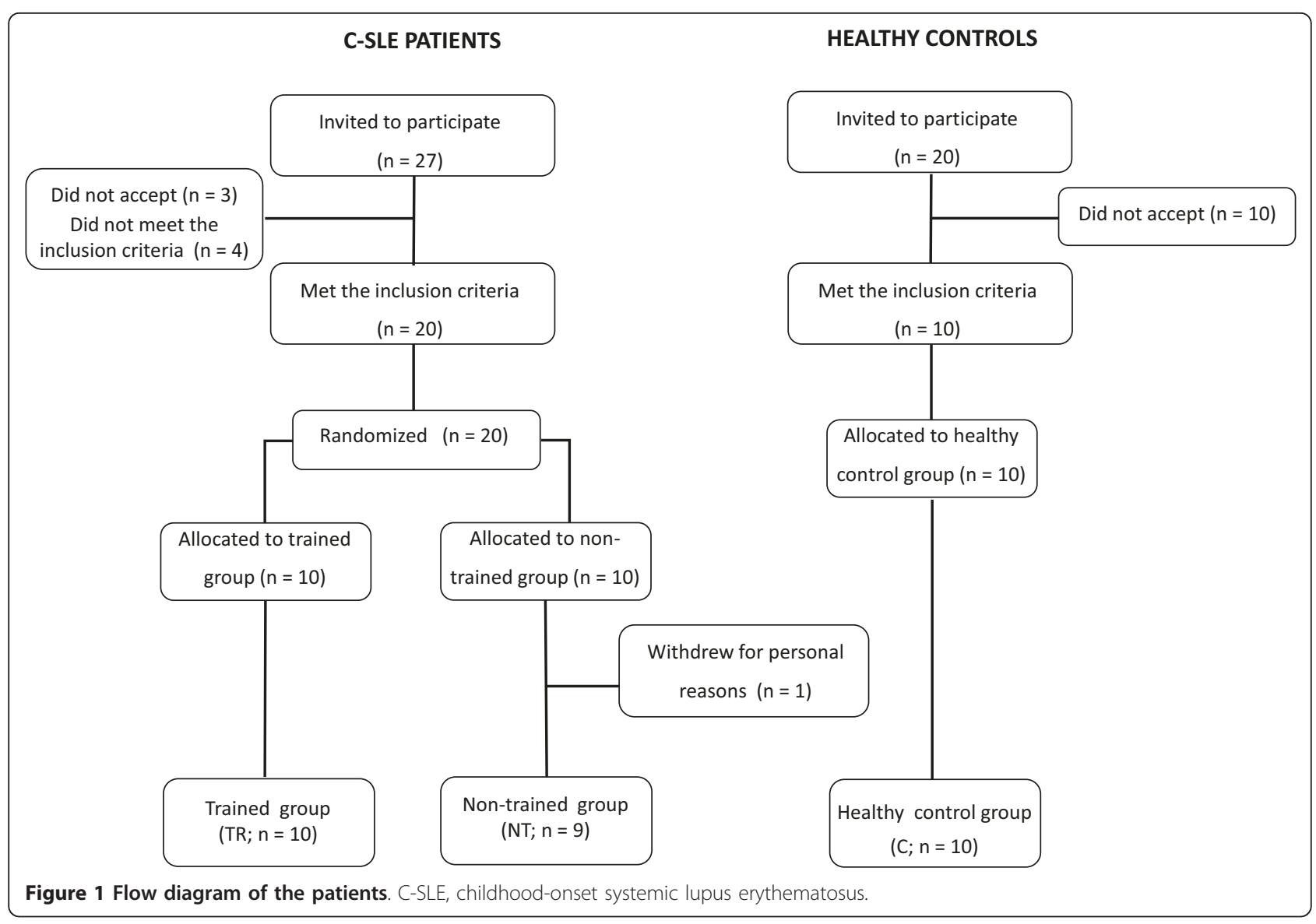

lower time-to-exhaustion, peak speed, peak $\mathrm{VO}_{2}$ and $\mathrm{CR}$ during the cardiorespiratory exercise test and higher resting HR when compared with the healthy control subjects $(P<0.05$, between-group comparisons). In addition, the relative change in $\mathrm{HR}(\Delta \%)$ from rest to VAT, rest to RCP, and rest to peak of exercise, and the HR recovery (that is, $\triangle$ HRR1 and $\triangle$ HRR2) were also significantly lower in the C-SLE patients when compared with healthy controls $(P<$ 0.05 , between-group comparisons). Importantly, all of the parameters were similar between the TR and NT groups ( $P>0.05$, between-group comparisons).

\section{Exercise tolerance and cardiorespiratory measurements after the exercise training program}

The exercise and cardiorespiratory parameters after the exercise training program are shown in Table 2. As expected, the NT group did not present any change in any of the parameters $(P<0.05$, within-group comparisons). In contrast, the TR group presented significant increases in time-to-exhaustion $(P=0.01, \mathrm{ES}=1.07)$ and peak speed $(P=0.01, \mathrm{ES}=1.08)$ and a decrease in resting HR $(P=$ 0.0002 , ES $=-1.45)$ when compared with the NT group. Additionally, the TR group had increased peak $\mathrm{VO}_{2}(P=$ $0.04, \mathrm{ES}=0.86), \mathrm{CR}(P=0.06, \mathrm{ES}=0.83)$, relative change in $\mathrm{HR}(\Delta \%)$ from rest to VAT $(P=0.0001, \mathrm{ES}=1.58$, rest to RCP $(P=0.0001, \mathrm{ES}=1.49)$, and rest to peak of exercise $(P=0.0003, \mathrm{ES}=1.53)$, and $\triangle \mathrm{HRR} 1(P=0.003, \mathrm{ES}=1.29)$ and $\triangle$ HRR2 $(P=0.0008, \mathrm{ES}=1.36)$ in comparison to the NT group. Moreover, after the aerobic exercise training program, the latter cardiorespiratory responses to exercise were comparable between the trained group and the healthy control group $(P>0.05)$ (Figures 2 and 3$)$.

\section{Clinical parameters, drug regimen, and adverse effects}

SLEDAI-2K scores remained unchanged throughout the study for both groups (TR: PRE $=5.0 \pm 5.1, \mathrm{POST}=3.8 \pm$ $3.8, P=0.71$, and NT: PRE $=5.5 \pm 6.4$, POST $=3.1 \pm 3.8$, $P=0.20$; within-group comparison).

Prednisone dosage was also unchanged in both groups after the intervention (TR: PRE $=14.8 \pm 11.1$, POST $=$ $12.5 \pm 7.2 \mathrm{mg} /$ day, $P=0.39$, and NT: $\mathrm{PRE}=13.8 \pm 6.5$, $\mathrm{POST}=12.5 \pm 5.8 \mathrm{mg} /$ day, $P=0.84$; within-group comparisons). Similarly, the other drugs (type and dose of medications) remained stable throughout the study. Additionally, the levels of ESR, CRP, C3 and C4 and antiDNAds antibodies were unaltered in both groups throughout the study $(P>0.05$, within-group comparison; data not shown). Finally, there was no clinical evidence of excessive 
Table 1 Demographic data at baseline

\begin{tabular}{|c|c|c|c|}
\hline Variable & $\begin{array}{l}\text { C-SLE trained } \\
(n=10)\end{array}$ & $\begin{array}{l}\text { C-SLE non-trained } \\
(n=9)\end{array}$ & $\begin{array}{l}\text { Control } \\
(n=10) \\
\end{array}$ \\
\hline Age, years & $12.9(2.3)$ & $13.0(1.8)$ & $12.0(1.8)$ \\
\hline Body weight, $\mathrm{Kg}$ & $48.7(10.1)$ & $49.7(12.1)$ & $46.6(14.5)$ \\
\hline Height, m & $1.48(0.09)$ & $1.44(0.11)$ & $1.51(0.13)$ \\
\hline Body mass index, $\mathrm{Kg} / \mathrm{m}^{2}$ & $22.3(3.8)$ & $23.9(3.4)$ & $21.2(1.7)$ \\
\hline Pubertal stages $|/||/| I / / I V N$, number of individuals & $1 / 2 / 2 / 2 / 3$ & $0 / 2 / 3 / 2 / 2$ & $3 / 2 / 1 / 2 / 2$ \\
\hline SLEDAI-2K, score & $5.3(5.3)$ & $5.6(6.4)$ & NA \\
\hline SLICC/ACR-DI, score & $0.4(0.7)$ & $0.4(0.7)$ & NA \\
\hline Disease duration, years & $3.3(2.6)$ & $4.3(2.6)$ & NA \\
\hline Current dose of prednisone, $\mathrm{mg} / \mathrm{d}$ & $19.8(17.0)$ & $15.5(7.7)$ & NA \\
\hline Cumulative dose of prednisone, $\mathrm{g}$ & $13.7(6.7)$ & $20.9(13.0)$ & NA \\
\hline Current dose of azathioprine, mg/d & $128.6(39.3)$ & $121.4(17.2)$ & NA \\
\hline Cumulative dose of azathioprine, $\mathrm{g}$ & $58.2(32.1)$ & $62.2(41.1)$ & NA \\
\hline Current dose of chloroquine, $\mathrm{g} / \mathrm{d}$ & $205.8(51.2)$ & $205.6(51.2)$ & NA \\
\hline Cumulative dose of chloroquine, $\mathrm{g}$ & $129.7(119.9)$ & $181.3(121.5)$ & NA \\
\hline \multicolumn{4}{|l|}{ Drugs, number of patients (\%) } \\
\hline Prednisone & $10(100)$ & $9(100)$ & \\
\hline Fluoxetine & $1(10)$ & $0(0)$ & NA \\
\hline Diltiazen & $1(10)$ & $0(0)$ & NA \\
\hline Enalapril & $3(30)$ & $5(55)$ & NA \\
\hline Losartan & $1(10)$ & $1(11)$ & NA \\
\hline Anlodipine & $0(0)$ & $2(22)$ & NA \\
\hline Carbamazepine & $1(10)$ & $0(0)$ & NA \\
\hline Methylphenidate & $0(0)$ & $0(0)$ & NA \\
\hline Clopidogrel & $0(0)$ & $0(0)$ & NA \\
\hline Warfarin & $1(10)$ & $0(0)$ & NA \\
\hline Acetylsalicylic Acid & $1(10)$ & $0(0)$ & NA \\
\hline
\end{tabular}

Results are presented as mean (SD) unless stated otherwise. C-SLE, childhood-onset systemic lupus erythematosus; SLEDAI, systemic lupus erythematosus disease activity index; SLICC/ACR-DI, Systemic Lupus International Collaborating Clinics/ACR Damage Index; NA, not applicable.

exhaustion, pain, osteoarticular injury, muscle soreness, or any other adverse event.

\section{BMD and body composition}

The TR, NT and C groups were similar in body composition and BMD parameters at baseline $(P>0.05$, betweengroup comparisons). Additionally, no significant changes were observed in any of these parameters after the intervention $(P>0.05$, within-group comparisons) (Table 3$)$.

\section{Discussion}

To the best of our knowledge, this is the first randomized controlled trial study aimed at investigating the effects of an exercise training program in a cohort of C-SLE patients. The main finding of this study is that a supervised aerobic exercise training program was safe and effective in improving the cardiorespiratory capacity in C-SLE patients.

C-SLE is commonly associated with poor physical function and low levels of physical activity $[11,12]$, possibly as a consequence of reduced cardiorespiratory capacity [8-12] and chronic fatigue [12]. Supporting this concept, we observed lower cardiorespiratory capacity (for example, lower peak $\mathrm{VO}_{2}$ ) and exercise tolerance (for example, lower time-to-exhaustion in the cardiorespiratory exercise test) in C-SLE patients when compared with their healthy peers. Moreover, we showed for the first time that C-SLE patients presented an abnormal HR response during and after the cardiorespiratory test (for example, low CR and delayed HR recovery), which are considered as important non-invasive markers of autonomic dysfunction [37-39]. Our results are in accordance with previous studies conducted with adult SLE patients where the same abnormal pattern was evidenced $[9,39]$. Notably, there is evidence showing that, at least in adult cohorts, low cardiorespiratory fitness and dysautonomia are associated with all-cause mortality and increased cardiovascular risk $[40,41]$. However, these relationships remain to be proven in SLE cohorts. In this context, strategies capable of improving the cardiorespiratory capacity and counteracting autonomic dysfunction are of upmost importance in the management of C-SLE patients who are already at increased CVD risk $[3,4]$. 
Table 2 Exercise tolerance and cardiorespiratory measurements before and after the exercise training

\begin{tabular}{lccc}
\hline Variable & $\begin{array}{c}\text { C-SLE } \\
\text { trained } \\
(n=10)\end{array}$ & $\begin{array}{c}\text { C-SLE non- } \\
\text { trained } \\
(n=9)\end{array}$ & $\begin{array}{c}\text { Control } \\
(n=10)\end{array}$ \\
\hline
\end{tabular}

Time-to-exhaustion,

minutes

\begin{tabular}{|c|c|c|c|}
\hline PRE & $10.1(2.2)^{a}$ & $9.7(1.6)^{\mathrm{a}}$ & $13.7(2.7)^{b}$ \\
\hline POST & $12.8(2.4)^{b}$ & $10.1(1.8)^{a}$ & - \\
\hline \multicolumn{4}{|c|}{ Resting heart rate, bpm } \\
\hline PRE & $102.6(10.3)^{a}$ & $106.1(12.1)^{\mathrm{a}}$ & $90.5(15.7)^{\mathrm{b}}$ \\
\hline POST & $86.2(13.8)^{b}$ & $110.6(8.4)^{\mathrm{a}}$ & - \\
\hline \multicolumn{4}{|c|}{ Peak heart rate, bpm } \\
\hline PRE & $178.2(18.3)^{\mathrm{a}}$ & $177.6(17.4)^{\mathrm{a}}$ & $195.8(8.9)^{\mathrm{a}}$ \\
\hline POST & $183.6(10.5)^{\mathrm{a}}$ & $178.1(18.6)^{\mathrm{a}}$ & - \\
\hline \multicolumn{4}{|c|}{ Peak $\mathrm{VO}_{2}, \mathrm{ml} / \mathrm{Kg} / \mathrm{min}$} \\
\hline PRE & $27.7(6.1)^{\mathrm{a}}$ & $25.7(3.1)^{\mathrm{a}}$ & $39.9(7.3)^{b}$ \\
\hline POST & $31.8(8.0)^{b}$ & $25.8(4.2)^{\mathrm{a}}$ & - \\
\hline \multicolumn{4}{|c|}{ Peak speed (Km/h) } \\
\hline PRE & $4.4(0.6)^{a}$ & $4.2(0.5)^{\mathrm{a}}$ & $5.4(0.9)^{b}$ \\
\hline POST & $5.2(0.8)^{b}$ & $4.3(0.5)^{a}$ & - \\
\hline \multicolumn{4}{|c|}{ Chronotropic reserve, \% } \\
\hline PRE & $75.5(18.7)^{\mathrm{a}}$ & $74.8(17.3)^{\mathrm{a}}$ & $96.6(8.2)^{b}$ \\
\hline POST & $87.1(9.0)^{\mathrm{b} *}$ & $74.1(18.9)^{\mathrm{a}}$ & - \\
\hline \multicolumn{4}{|c|}{ Heart rate, $\Delta \%$} \\
\hline \multicolumn{4}{|c|}{ Rest to VAT } \\
\hline PRE & $29.8(16.6)^{a}$ & $25.3(12.0)^{a}$ & $60.0(24.8)^{b}$ \\
\hline POST & $56.3(18.7)^{\mathrm{b}}$ & $17.0(9.5)^{a}$ & - \\
\hline \multicolumn{4}{|c|}{ Rest to RCP } \\
\hline PRE & $53.9(13.7)^{a}$ & $54.9(24.9)^{\mathrm{a}}$ & $97.3(35.9)^{\mathrm{b}}$ \\
\hline POST & $97.4(28.6)^{b}$ & $42.8(17.4)^{\mathrm{a}}$ & - \\
\hline \multicolumn{4}{|c|}{ Rest to Peak } \\
\hline PRE & $75.3(24.8)^{\mathrm{a}}$ & $68.9(22.9)^{a}$ & $\begin{array}{l}122.6 \\
(42.1)^{b}\end{array}$ \\
\hline POST & $117.7(34.3)^{b}$ & $61.5(16.6)^{\mathrm{a}}$ & - \\
\hline \multicolumn{4}{|c|}{$\begin{array}{l}\text { Heart rate recovery, } \\
\triangle H R R\end{array}$} \\
\hline \multicolumn{4}{|c|}{$\triangle \mathrm{HRR} 1$} \\
\hline PRE & $25.5(14.9)^{\mathrm{a}}$ & $26.6(10.0)^{\mathrm{a}}$ & $40.2(6.9)^{b}$ \\
\hline POST & $41.5(10.0)^{b}$ & $26.3(8.0)^{a}$ & - \\
\hline \multicolumn{4}{|c|}{$\triangle \mathrm{HRR2}$} \\
\hline PRE & $36.6(10.2)^{a}$ & $35.6(11.8)^{\mathrm{a}}$ & $57.8(8.9)^{b}$ \\
\hline POST & $62.2(13.7)^{b}$ & $39.8(9.7)^{a}$ & - \\
\hline
\end{tabular}

Data are expressed as means (SD) (mixed model for repeated measures). Relative change $(\Delta \%)$ for heart rate was calculated for the intervals between rest to ventilator anaerobic threshold (VAT), rest to respiratory compensation point $(\mathrm{RCP})$, and rest to peak of exercise. Absolute change $(\Delta)$ was used to calculate the difference between heart rate at peak exercise and at the first ( $\triangle \mathrm{HRR} 1)$ and second minutes $(\triangle \mathrm{HRR} 2)$ after the exercise test. Means with different letters are significantly different from each other $(P<0.05$, between- or within-group comparisons). ${ }^{*} P=0.06$, within-group comparison. C-SLE, childhood-onset systemic lupus erythematosus; PRE, pre-intervention (baseline), POST, postintervention; Peak, peak exercise; $\mathrm{VO}_{2}$, oxygen consumption.

Exercise has been shown to be a potential therapeutic tool in the management of adult SLE. Three pilot studies demonstrated that supervised exercise training can alleviate fatigue in adult SLE patients $[8,14,15]$. Furthermore, Tench et al. [42] observed improvements in fatigue after a three-month home-based exercise program. Similarly, Carvalho et al. [16], reported beneficial effects of a three-month exercise program on exercise tolerance, aerobic conditioning (for example, increased $\mathrm{VO}_{2 \max }$ ), and quality of life in SLE patients aged 18 to 55 years. Although these studies point out the potential therapeutic role of exercise in SLE, some limitations (such as lack of a randomized control design and small sample sizes) preclude definitive conclusions. Moreover, studies aimed at investigating the effects of exercise on physical capacity in pediatric rheumatologic patients are still scarce. Nonetheless, we have recently shown that a three-month combined endurance and resistance exercise training program induced improvements in the cardiorespiratory capacity (for example, increased $\mathrm{VO}_{2}$ peak and time-toexhaustion), muscle strength, and physical function in patients with JDM [23]. Furthermore, we also demonstrated that a three-month supervised aerobic exercise training program was capable of increasing $\mathrm{VO}_{2}$ peak and time-to-exhaustion in a 15 -year-old boy with antiphospholipid syndrome and C-SLE [25]. Importantly, the current findings extend the previous observations on the benefits of exercise in adult SLE and other pediatric rheumatologic patients to C-SLE.

Specifically, we showed that a three-month aerobic training program was effective in improving resting $\mathrm{HR}$ and peak $\mathrm{VO}_{2}$, peak speed, and time-to-exhaustion in a maximal graded exercise test in C-SLE patients. Noticeably, after the exercise training program, these parameters were comparable with those of their healthy peers, suggesting that the exercise training was effective in offsetting the C-SLE-related impairment in physical function and aerobic capacity.

Accordingly, we demonstrated that the exercise training program was also effective in attenuating the impaired $C R$ and the delayed post-exercise HR recovery in C-SLE patients, supporting the homeostatic role of exercise in C-SLE, particularly regarding the autonomic dysfunction. The present results corroborate the positive effects of exercise training upon autonomic control in adult patients with SLE [9] and CVD [43].

Children display a high bone turnover rate and a more pronounced change in bone mass in response to exercise training than later in life. In fact, we have previously demonstrated that a short-term (12 weeks) exercise training program comprising aerobic and resistance exercises was sufficient to increase BMAD in JDM patients [23]. Conversely, no changes in BMAD were observed in the present study. This result is somewhat expected as the C-SLE patients underwent only moderate-intensity aerobic exercise, which is unlikely to provide sufficient stimulus to promote bone mass accretion. Therefore, future 


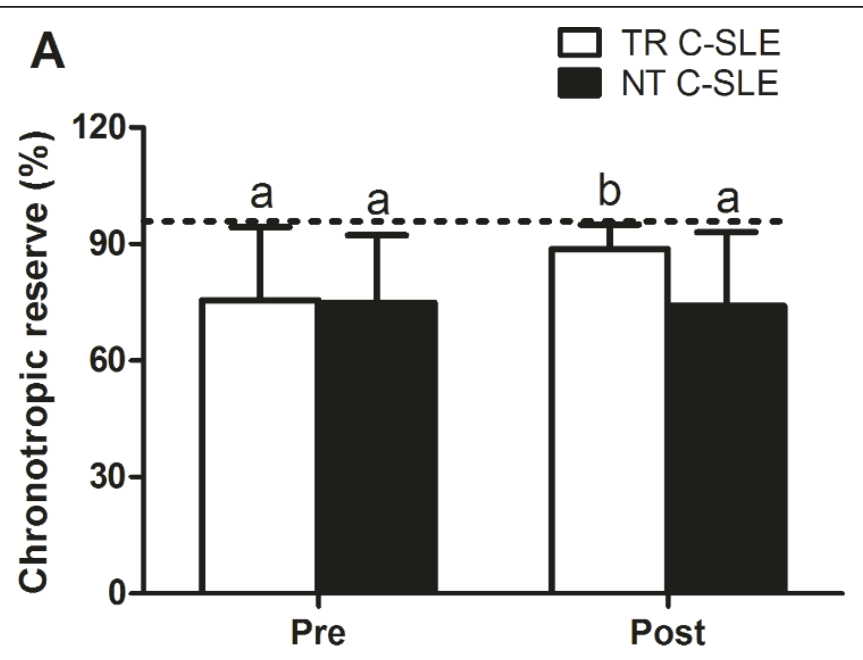

B

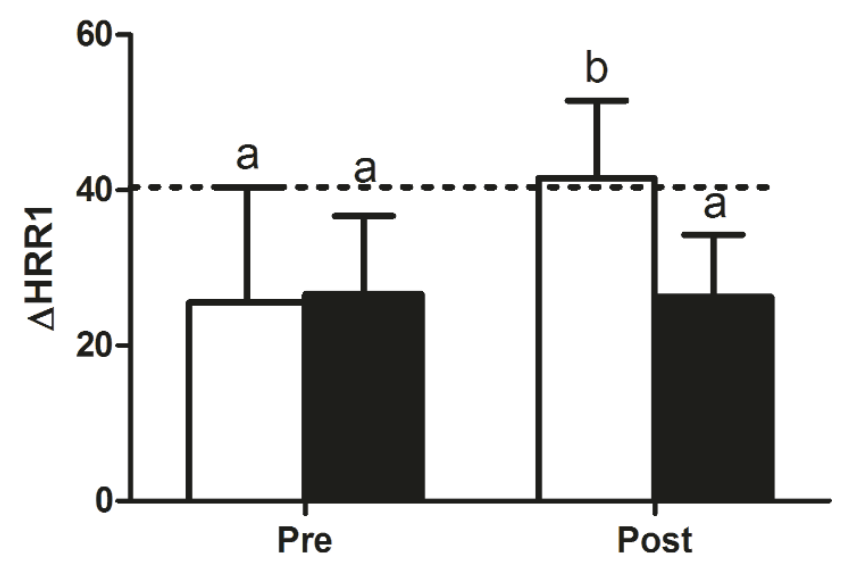

C

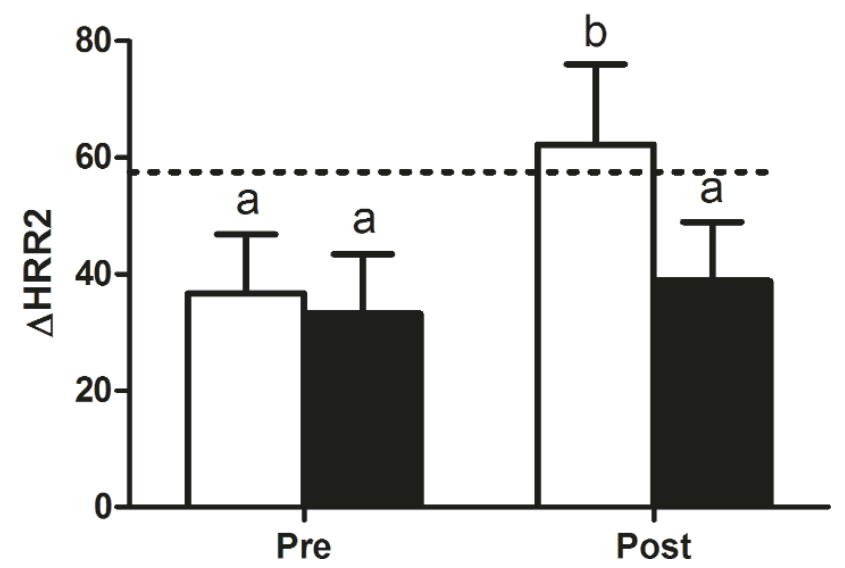

Figure 2 Cardiorespiratory measurements before (PRE) and after (POST) the exercise training. Dotted lines represent mean data from the healthy control group at baseline. (A) Chronotropic reserve. (B) Absolute change in heart rate at the first minute after exercise ( $\triangle \mathrm{HRR} 1)$. (C) Absolute change in heart rate at the second minute after exercise ( $\triangle$ HRR2). TR C-SLE, trained patients with childhood-onset systemic lupus erythematosus; NT C-SLE, non-trained patients with childhood-onset systemic lupus erythematosus. Means with different letters are significantly different from each other: a, significant difference when compared with the healthy control group; b, no significant difference when compared with the healthy control group. 

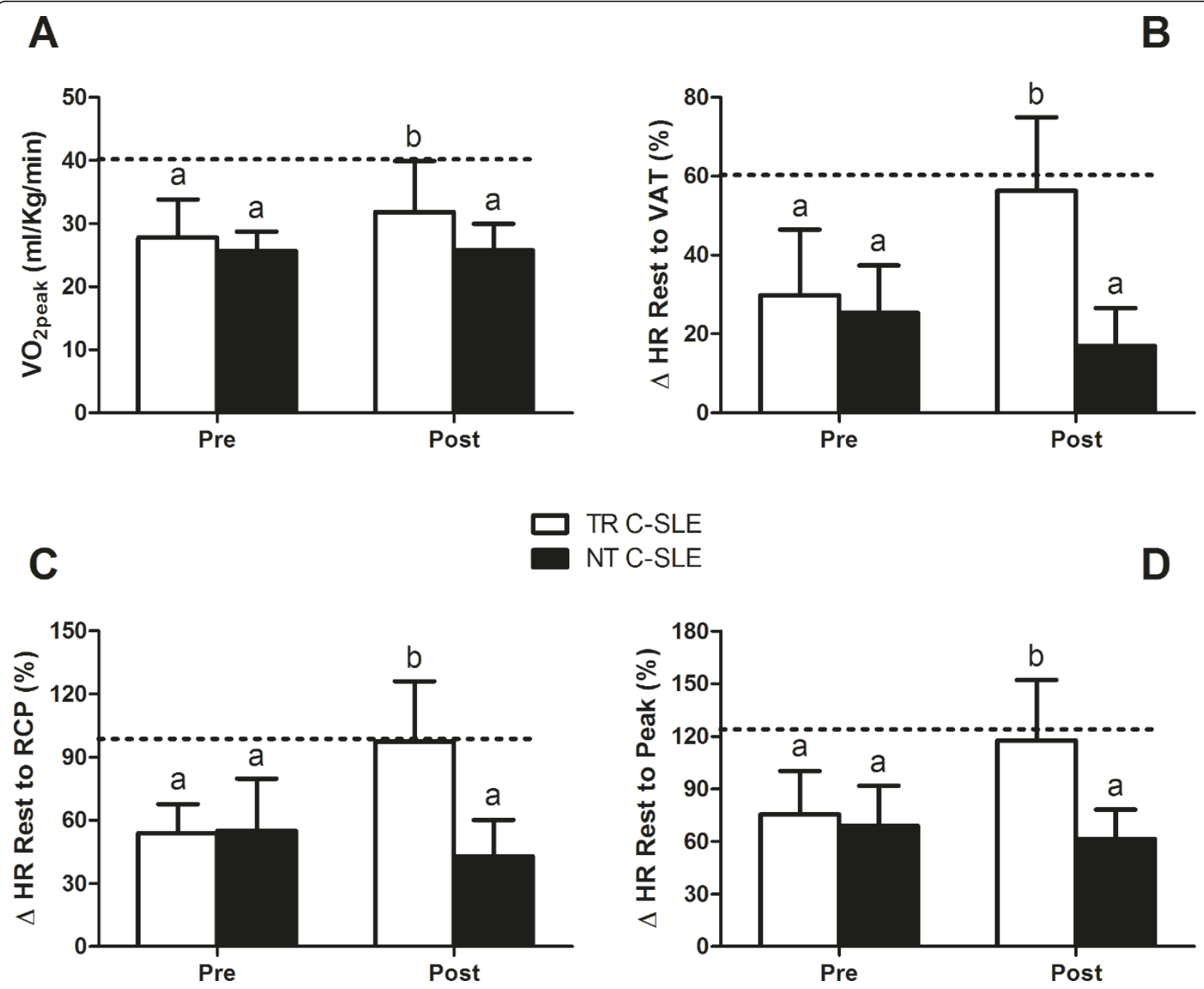

Figure 3 Cardiorespiratory measurements before (PRE) and after (POST) the exercise training. Dotted lines represent mean data from the healthy control group at baseline. (A) Peak oxygen consumption $\left(\mathrm{VO}_{2}\right.$ peak). (B) Relative change in heart rate $(\Delta \%)$ between rest and the ventilatory anaerobic threshold (VAT). (C) Relative change in heart rate $(\triangle \%)$ between rest and the respiratory compensation point (RCP). (D) Relative change in heart rate $(\Delta \%)$ between rest and peak exercise (Peak). TR C-SLE, trained patients with childhood-onset systemic lupus erythematosus; NT C-SLE, non-trained patients with childhood-onset systemic lupus erythematosus. Means with different letters are significantly different from each other: a, significant difference when compared with the healthy control group; b, no significant difference when compared with the healthy control group.

longer-term studies involving a more intensive aerobic and resistance training exercises should be performed to comprehensively examine the role of exercise on bone mass in C-SLE patients.

Finally, it is important to emphasize that the exercise training program did not provoke disease flare, as evidenced by lack of changes in disease activity scores and laboratory parameters of inflammation. Additionally, the drug regime was virtually unchanged throughout the study and no other adverse events were reported. Collectively, these findings suggest that a supervised moderateintensity aerobic training program may be safe for C-SLE patients, supporting previous studies with adult SLE patients $[8,9,14,15]$.

This study presents some limitations. First, our sample may be considered heterogeneous since the patients presented a large range of active disease scores. The selection of patients with different active disease scores was intentional and aimed at increasing the external validity of our study. However, we acknowledge that the number of patients enrolled in this trial did not allow us to compare the potential differential responses of active and non-active subjects to the exercise training. Therefore, further studies with larger samples comparing the exercise responses as a 
Table 3 Body composition, bone mineral apparent density (BMAD) and bone mineral content (BMC) before and after exercise training

\begin{tabular}{|c|c|c|c|}
\hline Variable & $\begin{array}{l}\text { C-SLE } \\
\text { trained } \\
(n=10)\end{array}$ & $\begin{array}{l}\text { C-SLE non- } \\
\text { trained } \\
(n=9)\end{array}$ & $\begin{array}{l}\text { Control } \\
(n=10)\end{array}$ \\
\hline \multicolumn{4}{|c|}{$\mathrm{BMAD}, \mathrm{L} 1-\mathrm{L} 4, \mathrm{~g} / \mathrm{cm}^{3}$} \\
\hline PRE & 0.097 (0.013) & $0.108(0.009)$ & $0.113(0.016)$ \\
\hline POST & $0.098(0.012)$ & $0.108(0.010)$ & - \\
\hline \multicolumn{4}{|c|}{$\mathrm{BMAD}, \mathrm{TF}, \mathrm{g} / \mathrm{cm}^{3}$} \\
\hline PRE & $0.133(0.019)$ & $0.145(0.017)$ & $0.163(0.032)$ \\
\hline POST & $0.134(0.020)$ & $0.145(0.021)$ & NA \\
\hline \multicolumn{4}{|c|}{ BMAD, WB without head, $\mathrm{g} / \mathrm{cm}^{3}$} \\
\hline PRE & $0.023(0.001)$ & $0.025(0.002)$ & $0.025(0.002)$ \\
\hline POST & $0.024(0.002)$ & $0.024(0.002)$ & NA \\
\hline \multicolumn{4}{|c|}{ Total BMC, g } \\
\hline PRE & $\begin{array}{l}1,223.0 \\
(270.4)\end{array}$ & $1,186.2(271.2)$ & $\begin{array}{l}1,530.0 \\
(567.7)\end{array}$ \\
\hline POST & $\begin{array}{l}1.245 .0 \\
(262.7)\end{array}$ & $1,221.2(252.7)$ & NA \\
\hline \multicolumn{4}{|c|}{$\begin{array}{l}\text { BMC, without head, } \\
\text { g }\end{array}$} \\
\hline PRE & $910.0(233.1)$ & $873.8(267.4)$ & $\begin{array}{l}1,168.3 \\
(508.0)\end{array}$ \\
\hline POST & $927.0(231.1)$ & $916.3(242.1)$ & NA \\
\hline \multicolumn{4}{|c|}{ Lean mass, $\mathrm{Kg}$} \\
\hline PRE & $31.5(4.9)$ & $29.9(7.6)$ & $33.9(10.8)$ \\
\hline POST & $31.8(5.1)$ & $30.7(7.4)$ & NA \\
\hline \multicolumn{4}{|c|}{ Fat mass, Kg } \\
\hline PRE & $17.4(7.3)$ & $16.8(6.0)$ & $11.7(7.2)$ \\
\hline POST & $17.0(7.9)$ & $19.1(6.3)$ & NA \\
\hline \multicolumn{4}{|l|}{ Height, m } \\
\hline PRE & $1.48(0.09)$ & $1.43(0.9)$ & $1.51(0.13)$ \\
\hline POST & 1.49 (0.09) & $1.44(0.1)$ & NA \\
\hline \multicolumn{4}{|c|}{ Weight, Kg } \\
\hline PRE & 48.7 (10.1) & $49.7(12.1)$ & 46.6 (14.5) \\
\hline POST & 49.7 (11.3) & $51.8(13.3)$ & NA \\
\hline
\end{tabular}

Data are expressed as means (SD) (mixed model for repeated measures). C-SLE, childhood-onset systemic lupus erythematosus; PRE, pre-intervention (baseline), POST, post-intervention; BMAD, bone mineral apparent density; $B M C$, bone mineral content; TF, total femur; L1-L4, lumbar vertebrae L1 to L4; WB, whole body; NA, not applicable. There were no significant differences between or within groups for any of the variables.

function of active disease are indeed necessary. Second, the healthy children did not participate in the exercise training program, thus precluding any comparison between patients and controls with respect to adaptive responses to exercise (for example, magnitude of changes). Finally, this was a short-term intra-hospital supervised intervention. Further studies should investigate the efficacy, safety and feasibility of other training program (such as, recreational physical activity, sports-related activities, physical education classes, and home-based programs). Moreover, it is imperative to investigate the long-term effects of exercise (or spontaneous physical activity) in more robust outcomes (for example, incidence of institutionalization, disease flares, health-related quality of life, cardiovascular events and lipid and bone metabolism).

\section{Conclusions}

In conclusion, this study demonstrated for the first time that a three-month supervised moderate-intensity aerobic exercise training program can be safe and effective in ameliorating the cardiorespiratory capacity and the autonomic function in C-SLE patients. These findings stress the potential role of exercise training in the management of C-SLE, strengthening previous evidence of the beneficial effects of exercise in other pediatric rheumatic diseases.

\begin{abstract}
Abbreviations
$\mathrm{BA}$ : bone area; BMAD: bone mineral apparent density; BMC: bone mineral content; BMD: bone mineral density; BMl: body mass index; $\mathrm{C}$ : healthy control group; C3: complement 3; C4: complement 4; CR: chronotropic reserve; CRP: C-reactive protein; C-SLE: childhood-onset systemic lupus erythematosus; CVD: cardiovascular disease; $\triangle H R R$ : heart rate recovery; $\triangle H R R 1$ : heart rate recovery at the first minute; $\triangle H R R 2$ : heart rate recovery at the second minute; DXA: dual-energy x-ray absorptiometry; ES: effect size; ESR: erythrocyte sedimentation rate; HR: heart rate; JDM: juvenile dermatomyositis; NT: non-trained C-SLE group; POST: 12 weeks postintervention; PRE: pre-intervention (baseline); RCP: respiratory compensation point; RER: respiratory exchange ratio; SLE: systemic lupus erythematosus; SLEDAl: systemic lupus erythematosus disease activity index; SLICC/ACR-DI: Systemic Lupus International Collaborating Clinics/ACR Damage Index; TR: trained C-SLE group; VAT: ventilatory anaerobic threshold; $\mathrm{VO}_{2}$ : oxygen consumption; $\mathrm{VO}_{2}$ peak: peak oxygen consumption.
\end{abstract}

\section{Authors' contributions}

Study conception and design: DMLP, CAS, BG, ALSP, EB, and HR. Acquisition of data: DMLP, CAS, AMES, RMRP, APH, and FBB. Analysis and interpretation of data: DMLP, CAS, AEMS, FBB, RMRP, ALSP, APH, BG, EB, and HR. All of the authors were involved in drafting the article or revising it critically for important intellectual content, and all of the authors approved the final version to be submitted for publication. The authors had full access to all of the data in the study and take responsibility for the integrity of the data and the accuracy of the data analysis.

\section{Competing interests}

The authors declare that they have no conflicts of interest.

\section{Acknowledgements}

This study was supported by Fundação de Amparo a Pesquisa do Estado de São Paulo (FAPESP; 2011/08302-0 for FBB), by Conselho Nacional do Desenvolvimento Científico e Tecnológico (CNPQ - 300559/2009-7 to RMRP and 302724/2011-7 to CAS), by Federico Foundation to RMRP and CAS, and by Núcleo de Apoio à Pesquisa 'Saúde da Criança e do Adolescente' da USP (NAP-CriAd) to CAS.

\section{Author details}

${ }^{1}$ Division of Rheumatology, School of Medicine, University of Sao Paulo, Av. Dr. Eneas de Carvalho Aguiar, 255 - Sao Paulo, SP, CEP 05403-000, Brazil. ${ }^{2}$ School of Physical Education and Sport, University of Sao Paulo, Rua Professor Mello Moraes, 65- Sao Paulo, SP, CEP 05025-010, Brazil. ${ }^{3}$ Pediatric Rheumatology Unit, Children's Institute, School of Medicine, University of Sao Paulo, Av. Dr. Arnaldo, 455 - Cerqueira César, Sao Paulo, SP, CEP 01246 903, Brazil.

Received: 17 October 2012 Revised: 22 January 2013 Accepted: 19 March 2013 Published: 26 March 2013 


\section{References}

1. Kamphuis S, Silverman ED: Prevalence and burden of pediatric-onset systemic lupus erythematosus. Nat Rev Rheumatol 2010, 6:538-546.

2. González B, Hernández P, Olguín H, Miranda M, Lira L, Toso M, Quezada A, Norambuena X, Talesnik E, Méndez C, Navarrete C: Changes in the survival of patients with systemic lupus erythematosus in childhood: 30 years experience in Chile. Lupus 2005, 14:918-923.

3. Levy DM, Kamphuis S: Systemic lupus erythematosus in children and adolescents. Pediatr Clin North Am 2012, 59:345-364.

4. Benseler SM, Silverman ED: Systemic lupus erythematosus. Rheum Dis Clin North Am 2007, 33:471-498.

5. Chung CP, Avalos I, Oeser A, Gebretsadik T, Shintani A, Raggi P, Michael Stein C: High prevalence of the metabolic syndrome in patients with systemic lupus erythematosus: association with disease characteristics and cardiovascular risk factors. Ann Rheum Dis 2007, 66:208-214.

6. El Magadmi M, Ahmad Y, Turkie W, Yates AP, Sheikh N, Bernstein RM, Durrington PN, Laing I, Bruce IN: Hyperinsulinemia, insulin resistance, and circulating oxidized low density lipoprotein in women with systemic lupus erythematosus. J Rheumatol 2006, 33:50-56.

7. Aydemir M, Yazisiz V, Basarici I, Avci AB, Erbasan F, Belgi A, Terzioglu E: Cardiac autonomic profile in rheumatoid arthritis and systemic lupus erythematosus. Lupus 2010, 19:255-261

8. Robb-Nicholson LC, Daltroy L, Eaton H, Gall V, Wright E, Hartley LH, Schur $\mathrm{PH}$, Liang MH: Effects of aerobic conditioning in lupus fatigue: a pilot study. Br J Rheumatol 1989, 28:500-505.

9. Miossi R, Benatti FB, Luciade de Sa Pinto A, Lima FR, Borba EF, Prado DM, Perandini LA, Gualano B, Bonfa E, Roschel H: Using exercise training to counterbalance chronotropic incompetence and delayed heart rate recovery in systemic lupus erythematosus: A randomized trial. Arthritis Care Res (Hoboken) 2012, 64:1159-1166.

10. Daltroy LH, Robb-Nicholson C, Iversen MD, Wright EA, Liang MH: Effectiveness of minimally supervised home aerobic training in patients with systemic rheumatic disease. $\mathrm{Br} J$ Rheumatol 1995, 34:1064-1069.

11. Tench C, Bentley D, Vleck V, McCurdie I, White P, D'Cruz D: Aerobic fitness, fatigue, and physical disability in systemic lupus erythematosus. J Rheumatol 2002, 29:474-481.

12. Houghton KM, Tucker LB, Potts JE, McKenzie DC: Fitness, fatigue, disease activity, and quality of life in pediatric lupus. Arthritis Rheum 2008 59:537-545.

13. Kodama S, Saito K, Tanaka S, Maki M, Yachi Y, Asumi M, Sugawara A, Totsuka K, Shimano H, Ohashi Y, Yamada N, Sone H: Cardiorespiratory fitness as a quantitative predictor of all-cause mortality and cardiovascular events in healthy men and women: a meta-analysis. JAMA 2009, 301:2024-2035

14. Ramsey-Goldman R, Schilling EM, Dunlop D, Langman C, Greenland P, Thomas RJ, Chang RW: A pilot study on the effects of exercise in patients with systemic lupus erythematosus. Arthritis Care Res 2000, 13:262-269.

15. Clarke-Jenssen AC, Fredriksen PM, Lilleby V, Mengshoel AM: Effects of supervised aerobic exercise in patients with systemic lupus erythematosus: a pilot study. Arthritis Rheum 2005, 53:308-312

16. Carvalho MR, Sato El, Tebexreni AS, Heidecher RT, Schenkman S, Neto TL: Effects of supervised cardiovascular training program on exercise tolerance, aerobic capacity, and quality of life in patients with systemic lupus erythematosus. Arthritis Rheum 2005, 53:838-844.

17. Bar-Or O, Rowland TW: Pediatric Exercise Medicine: From Physiologic Principles to Health Care Application. Champaign: Human Kinectics; 2004.

18. Carreno L, Lopez-Longo FJ, Monteagudo I, Rodriguez-Mahou M, Bascones M, Gonzalez CM, Saint-Cyr C, Lapointe N: Immunological and clinical differences between juvenile and adult onset of systemic lupus erythematosus. Lupus 1999, 8:287-292.

19. Hoffman IE, Lauwerys BR, De Keyser F, Huizinga TW, Isenberg D, Cebecauer L, Dehoorne J, Joos R, Hendrickx G, Houssiau F, Elewaut D: Juvenile-onset systemic lupus erythematosus: different clinical and serological pattern than adult-onset systemic lupus erythematosus. Ann Rheum Dis 2009, 68:412-415.

20. Araujo DB, Borba EF, Silva CA, Campos LM, Pereira RM, Bonfa E, Shinjo SK: Alveolar hemorrhage: distinct features of juvenile and adult onset systemic lupus erythematosus. Lupus 2012, 21:872-877.

21. Ardoin SP, Schanberg LE: Paediatric rheumatic disease: lessons from SLE: children are not little adults. Nat Rev Rheumatol 2012, 8:444-445.
22. Omori C, Prado DM, Gualano B, Sallum AM, Sa-Pinto AL, Roschel H, Perondi MB, Silva CA: Responsiveness to exercise training in juvenile dermatomyositis: a twin case study. BMC Musculoskelet Disord 2010, $11: 270$.

23. Omori CH, Silva CA, Sallum AM, Rodrigues Pereira RM, Luciade Sa Pinto A, Roschel $H$, Gualano B: Exercise training in juvenile dermatomyositis. Arthritis Care Res (Hoboken) 2012, 64:1186-1194.

24. Stephens S, Feldman BM, Bradley N, Schneiderman J, Wright V, SinghGrewal D, Lefebvre A, Benseler SM, Cameron B, Laxer R, O'Brien C, Schneider R, Silverman E, Spiegel L, Stinson J, Tyrrell PN, Whitney K, Tse SM: Feasibility and effectiveness of an aerobic exercise program in children with fibromyalgia: results of a randomized controlled pilot trial. Arthritis Rheum 2008, 59:1399-1406.

25. Prado DM, Gualano B, Pinto AL, Sallum AM, Perondi MB, Roschel H, Silva CA: Exercise in a child with systemic lupus erythematosus and antiphospholipid syndrome. Med Sci Sports Exerc 2011, 43:2221-2223.

26. Gualano B, Sa Pinto AL, Perondi B, Leite Prado DM, Omori C, Almeida RT, Sallum AM, Silva CA: Evidence for prescribing exercise as treatment in pediatric rheumatic diseases. Autoimmun Rev 2010, 9:569-573.

27. Hochberg MC: Updating the American College of Rheumatology revised criteria for the classification of systemic lupus erythematosus. Arthritis Rheum 1997, 40:1725.

28. Gladman DD, Ibanez D, Urowitz MB: Systemic lupus erythematosus disease activity index 2000. J Rheumatol 2002, 29:288-291.

29. Brunner HI, Silverman ED, To T, Bombardier C, Feldman BM: Risk factors for damage in childhood-onset systemic lupus erythematosus: cumulative disease activity and medication use predict disease damage. Arthritis Rheum 2002, 46:436-444.

30. Braga A, Nunes N: Avaliação Cardiopulmonar. Cardiologia do Exercício: do Atleta ao Cardiopata. 1 edition. São Paulo: Manole; 2005, 128-147.

31. Rowland TW: Aerobic exercise testing protocols. Pediatric Laboratory Exercise Testing Champaign: Human Kinects; 1993, 19-41.

32. Machado F, Denadai B: Validade das Equações Preditivas da Frequência Cardíaca Máxima para Crianças e Adolescentes. Ara Bras Cardiol 2011 97:136-140.

33. Taylor A, Konrad PT, Norman ME, Harcke HT: Total body bone mineral density in young children: influence of head bone mineral density. J Bone Miner Res 1997, 12:652-655.

34. Crabtee N, Leonard M, Zemel B: Dual-energy x-ray absorptiometry. In Bone densitometry in growing patients: guidelines for clinical practice. Edited by: Sawyer A, Bachrach L, Funch E. Totowa, NJ: Humana Press Inc; 2007:41-57.

35. Baim S, Wilson CR, Lewiecki EM, Luckey MM, Downs RW Jr, Lentle BC Precision assessment and radiation safety for dual-energy X-ray absorptiometry: position paper of the International Society for Clinical Densitometry. J Clin Densitom 2005, 8:371-378.

36. Cohen J: Statistical power analysis for the behavioral sciences. Hillsdale, USA: Lawrence Erlbaum Associates; 21988.

37. Rosenwinkel ET, Bloomfield DM, Arwady MA, Goldsmith RL: Exercise and autonomic function in health and cardiovascular disease. Cardiol Clin 2001, 19:369-387.

38. do Prado DL, Gualano B, Miossi R, Sa-Pinto A, Lima F, Roschel H, Borba E, Bonfa $\mathrm{E}$ : Abnormal chronotropic reserve and heart rate recovery in patients with SLE: a case-control study. Lupus 2011, 20:717-720.

39. Dogdu O, Yarlioglues M, Kaya MG, Ardic I, Oguzhan N, Akpek M, Sahin O, Akyol L, Kelesoglu S, Koc F, Ozdogru I, Oguzhan A: Deterioration of heart rate recovery index in patients with systemic lupus erythematosus. J Rheumatol 2010, 37:2511-2515.

40. Nishime EO, Cole CR, Blackstone EH, Pashkow FJ, Lauer MS: Heart rate recovery and treadmill exercise score as predictors of mortality in patients referred for exercise ECG. JAMA 2000, 284:1392-1398.

41. Cole CR, Blackstone EH, Pashkow FJ, Snader CE, Lauer MS: Heart-rate recovery immediately after exercise as a predictor of mortality. $N$ Engl J Med 1999, 341:1351-1357.

42. Tench CM, McCarthy J, McCurdie I, White PD, D'Cruz DP: Fatigue in systemic lupus erythematosus: a randomized controlled trial of exercise. Rheumatology (Oxford) 2003, 42:1050-1054.

43. Keteyian SJ, Brawner CA, Schairer JR, Levine TB, Levine AB, Rogers FJ, Goldstein S: Effects of exercise training on chronotropic incompetence in patients with heart failure. Am Heart J 1999, 138:233-240. 
doi:10.1186/ar4205

Cite this article as: Prado et al: Exercise training in childhood-onset systemic lupus erythematosus: a controlled randomized trial. Arthritis Research \& Therapy 2013 15:R46.

Submit your next manuscript to BioMed Central and take full advantage of:

- Convenient online submission

- Thorough peer review

- No space constraints or color figure charges

- Immediate publication on acceptance

- Inclusion in PubMed, CAS, Scopus and Google Scholar

- Research which is freely available for redistribution

Submit your manuscript at 